\title{
Development of a Nonenzymatic Electrochemical Sensor for Organophosphate Pesticide Detection Using Copper (II) Oxide Nanorod Electrodes
}

\author{
Phichamon Sakdarat $\mathbb{D},{ }^{1}$ Jidapa Chongsuebsirikul $\mathbb{D}^{1},{ }^{1}$ Chanchana Thanachayanont $\mathbb{D},{ }^{2}$ \\ Seeroong Prichanont $\mathbb{D}^{3},{ }^{3}$ and Porpin Pungetmongkol ${ }^{1}{ }^{1}$ \\ ${ }^{1}$ International School of Engineering (ISE), Faculty of Engineering, Chulalongkorn University, Bangkok 10330, Thailand \\ ${ }^{2}$ National Metal and Materials Technology Center (MTEC), National Science and Technology Development Agency, \\ Pathumthani 12120, Thailand \\ ${ }^{3}$ Department of Chemical Engineering, Faculty of Engineering, Chulalongkorn University, Bangkok 10330, Thailand
}

Correspondence should be addressed to Porpin Pungetmongkol; porpin.p@chula.ac.th

Received 23 November 2020; Revised 5 May 2021; Accepted 12 July 2021; Published 29 July 2021

Academic Editor: Hassan Azzazy

Copyright ( 2021 Phichamon Sakdarat et al. This is an open access article distributed under the Creative Commons Attribution License, which permits unrestricted use, distribution, and reproduction in any medium, provided the original work is properly cited.

\begin{abstract}
Inorganic electrode materials of low cost, lower complexity, and high stability have become the more preferred choice over enzyme usage in electrochemical sensors. In this work, copper oxide $(\mathrm{CuO})$ nanorods (NRs) were synthesized on copper foil as electrodes through anodization and annealing processes. The synthesized electrodes were used to analyse the organophosphate pesticides (OPPs) and interference molecules by cyclic voltammetry. The CuO NR sensor was able to identify and quantify different kinds of OPPs with an elevated sensitivity of $1.269,1.425,1.657$, and $2.833 \mu \mathrm{A} / \mathrm{ng} \mathrm{mL}^{-1}$ for chlorpyrifos, parathion, paraoxon, and pirimiphos and explicitly separate them from interference molecules (i.e., carbaryl, paraquat, sodium nitrate, sodium sulphate, and toluene). Moreover, this electrochemical pesticide sensor achieved a very low limit of detection (LOD) in the $10^{-7}$ molar level with a high selectivity among all tested analytes. The LOD for each pesticide ranged from 0.29 to $0.61 \mu \mathrm{M}$, revealing the ability to define the maximum residue limit in food. In short, our enzyme-free $\mathrm{CuO} N R$ sensor is a promising platform to deliver a fast, low-cost, and reliable pesticide detection unit.
\end{abstract}

\section{Introduction}

Pesticides are used intensively to increase crop yields. However, concern for food safety has increased recently and many countries have strived to prohibit the usage of toxic farm chemicals, including organophosphate (OP) pesticides (OPPs). Long-term intake of OPs cause many serious health problems, for example, neurotoxic effect, asthma, coronary artery disease, and cancer [1-4]. The demand for a pesticide residue detector has risen for regulation control and industrial waste management and prospectively for household usage.

The conventional techniques for pesticide analysis, such as gas chromatography $[5,6]$, liquid chromatography $[7,8]$, mass spectrometry $[9,10]$, and electrophoresis $[10,11]$, are impractical for general application due to the high cost of the machine setup, need for specialist operators, difficulty in sample preparation, and incapability of real-time sensing. Thus, a more simple detection system of electrochemical sensors has emerged as a substitute for the aforementioned large-scale equipment [12]. Many electrochemical sensor platforms that possess a fast, real-time, and simple analysis have been proposed for pesticide detection [13-15].

The first-generation pesticide electrochemical sensors exploited the well-known acetylcholinesterase enzyme inhibition assay to detect pesticide residues [16-19]. This enzyme-based pesticide sensor was found to possess high sensitivity and selectivity towards OPPs, but its low stability, low electrical conductivity, and high costs halted it from being available in a practical application [20-24]. Therefore, a new generation of nonenzymatic electrode pesticide 
sensors was developed utilizing diverse inorganic materials to detect the pesticide residues. These sensors had a higher stability, longer storage life, and better reproducibility [2527]. Moreover, those nonenzyme electrodes provided easy incorporation of nanomaterials on their surface and demonstrated a drastic enhancement in both their sensitivity and selectivity [28-32].

The sensor platform has since been shifted towards being portable and wearable devices, which require a high stability electrode using nonenzymatic materials [33]. Apart from many inorganic materials, the transition metal copper $(\mathrm{Cu})$ presents a high affinity towards the thionate or oxonate group of OPPs via a coordinate covalent bond [34-36], as depicted in Figure 1. The use of $\mathrm{Cu}$ powder mixed with carbon ink for a screen-printed electrode was utilized to detect carbohydrate. However, the measured current range was comparatively low in the microampere level, and so, it was not highly sensitive [37]. In this work, thin $\mathrm{Cu}$ foil was selected as a high conductive electrode material and the nanostructure was fabricated on the $\mathrm{Cu}$ foil surface with seamless techniques. Simple and low-cost methods were chosen to create the desired copper oxide nanorod (CuO NR) electrodes using anodization and annealing processes. The $\mathrm{CuO} \mathrm{NR}$ structure presented a high affinity and sensitivity towards sample molecules as pesticides.

Qualitative and quantitative analyses of pesticides were carefully conducted by electrochemical measurement. During the cyclic voltammetry $(\mathrm{CV})$ analysis, the potential was gradually swept from a negative to a positive potential applied at the $\mathrm{Cu}$ working electrode in a $0.25 \mathrm{M}$ sodium hydroxide $(\mathrm{NaOH})$ solution. At the oxidation potential of cuprous oxide $\left(\mathrm{Cu}_{2} \mathrm{O}\right)$, around $0.05 \mathrm{~V}$, the electrode is oxidized to $\mathrm{CuO}$ and generates two electrons, as shown in Equation (1) [38]:

$$
\mathrm{Cu}_{2} \mathrm{O}+2 \mathrm{OH}^{-} \longrightarrow 2 \mathrm{CuO}+\mathrm{H}_{2} \mathrm{O}+2 \mathrm{e}^{-}
$$

The current generated from the redox reaction of $\mathrm{Cu}_{2} \mathrm{O}$ corresponds to the oxidation peak in the CV measurement. In the presence of pesticide, the $\mathrm{CuO}$ forms coordinated bonds with the thionate or oxonate group of the OPP, which blocks the site for the standard redox to proceed (Figure 1), resulting in a drop in the oxidation current peak. Since the decreased current magnitude is directly related to the amount of pesticide added to the system, it can be used for quantitative analysis of OPP levels. For selectivity analysis, other pesticide groups (i.e., carbaryl and paraquat) and some common molecules (i.e., toluene, sodium sulphate, and sodium nitrate) lacking phosphate or phosphothionate groups were also included in this study (Figure 2).

\section{Materials and Methods}

2.1. Reagents and Materials. Pure Cu foil C110 (99.9\% purity, $0.11 \mathrm{~mm}$ thickness) was purchased from Shanghai Metal Corporation. Ethanol, acetone, and hydrochloric acid $(\mathrm{HCl})$ were bought from QReC chemical Co., Ltd. Potassium hydroxide $(\mathrm{KOH})$ and $\mathrm{NaOH}$ were purchased from Thermo Fisher Scientific. Chlorpyrifos, pirimiphos, parathion, and

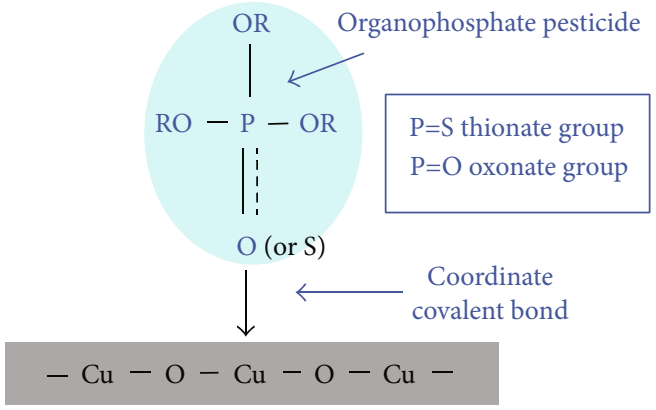

Figure 1: Schematic of the prospective coordinate covalent bond between the thionate or oxonate functional group of OPPs with the $\mathrm{CuO} \mathrm{NO}$ sensor.

paraoxon were purchased from Sigma-Aldrich and prepared by diluting in $1: 19(v / v)$ ethanol: deionized water to different concentrations. All prepared solutions were diluted with deionized water $(18.0 \mathrm{M} \Omega \mathrm{cm})$. The purchased chemicals and reagents were of analytical grade and used as received without any further purifications.

2.2. Synthesis of $\mathrm{CuO}$ NRs. The $\mathrm{CuO} \mathrm{NR}$ arrays were synthesized by anodization of $\mathrm{Cu}$ foil and a controlled annealing process. Pure $\mathrm{Cu}$ foil (C110) was cut and cleaned with $\mathrm{HCl}$ and acetone for $1 \mathrm{~min}$ each, as reported [39, 40]. The acidwashed $\mathrm{Cu}$ foil was then anodized in $3.0 \mathrm{M} \mathrm{KOH}$ solution by applying a constant current density of $1.5 \mathrm{~mA} / \mathrm{cm}^{2}$ in a three-electrode system using a platinum auxiliary electrode and a silver-silver chloride $(\mathrm{Ag} / \mathrm{AgCl})$ reference electrode. The oxidation reactions occurred at the anode, forming copper (II) hydroxide $\left(\mathrm{Cu}(\mathrm{OH})_{2}\right)$, and the reduction reaction at the cathode, releasing hydrogen gas. The anodization time was varied $(15,20,25$, and $30 \mathrm{~min})$ to observe the differences in physical properties that were related to the electrochemical characteristics of the fabricated $\mathrm{CuO}$ NRs. The anodized $\left(\mathrm{CuO} / \mathrm{Cu}(\mathrm{OH})_{2}\right.$ coated) $\mathrm{Cu}$ foil was washed with distilled water and dried at room temperature. Finally, the $\mathrm{Cu} / \mathrm{Cu}(\mathrm{OH})_{2}$ electrode was annealed at $200^{\circ} \mathrm{C}$ for $1 \mathrm{~h}$ to completely remove water and obtain the crystalline phases of $\mathrm{CuO}$ NRs. As a result, a $\mathrm{CuO}$ NR structure was obtained on the electrodes. Figure 3 schematically illustrates a summary of the electrode's fabrication procedure, while real images of the fabricated electrode at each stage are presented in Figure 4. The cleaned $\mathrm{Cu}$ foils after anodization presented a faint blue colour, confirming the formation of $\mathrm{Cu}(\mathrm{OH})_{2}$, and these then turned dark brown after annealing due to the formation of $\mathrm{CuO}$. Finally, the electrodes were cut and painted with nail polish to define the area of detection to $3 \mathrm{~mm}$ width $\times 3 \mathrm{~mm}$ length $\left(0.09 \mathrm{~cm}^{2}\right)$.

2.3. Material Characterizations. The physical characteristics, e.g., surface morphology, elemental composition, and crystallography, of the modified electrodes were examined to visualize the fabrication results and further verified by electrochemical analysis response. The crystallographic information of nanostructure was investigated using X-ray diffractometry (XRD; Bruker AXS Model D8 Discover) with a generator voltage of $40 \mathrm{kV}$ and tube current of $40 \mathrm{~mA}$. 
<smiles></smiles>
Chlorpyrifos<smiles>C[n+]1ccc(-c2cc[n+](C)cc2)cc1</smiles><smiles>CCOP(=S)(OCC)Oc1cc(C)nc(N(CC)CC)n1</smiles><smiles>CNC(=O)Oc1cccc2ccccc12</smiles><smiles>COP(=S)(OC)Oc1ccc([N+](=O)[O-])cc1</smiles><smiles>Cc1ccccc1</smiles><smiles>CCOP(=O)(OCC)Oc1ccc([N+](=O)[O-])cc1</smiles><smiles>O=S(=O)(O[Na])O[Nb]</smiles><smiles>N[N+](=O)[O-]</smiles>

Sodium sulphate

Sodium nitrate

FIGURE 2: Chemical structure of the OPPs (chlorpyrifos, pirimiphos, parathion, and paraoxon), non-OPPs (carbaryl and paraquat), and other common molecules (i.e., toluene, sodium sulphate, and sodium nitrate) used as analytes in this study.

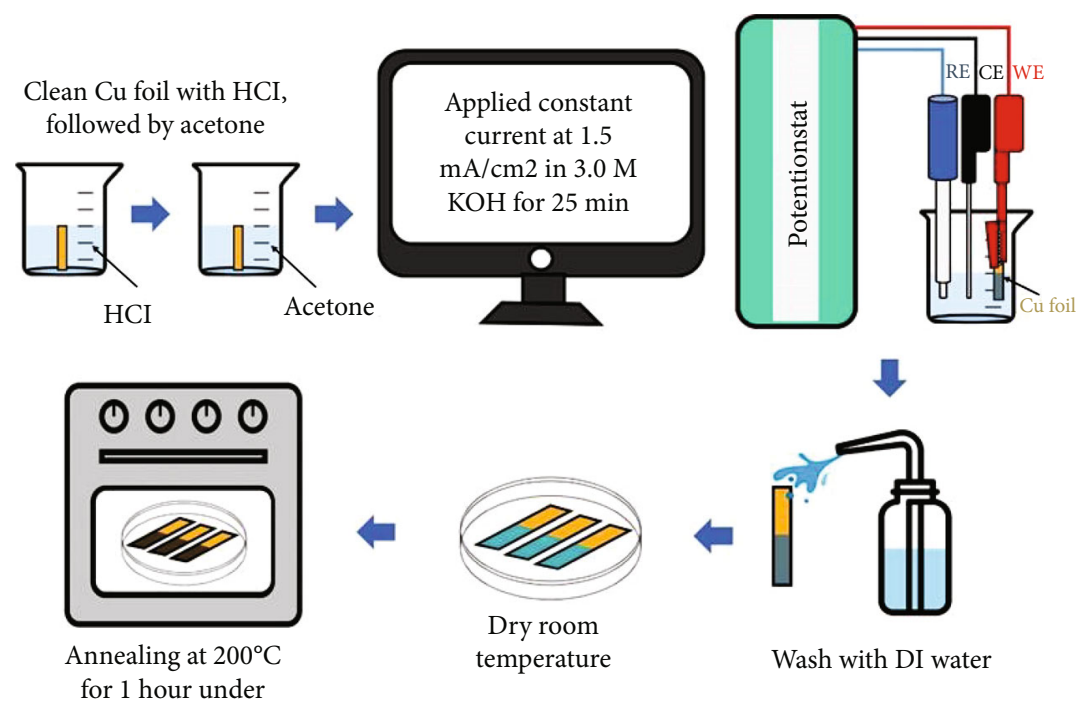

FIGURE 3: Schematic overview of the fabrication process of $\mathrm{CuO}$ NR electrode.

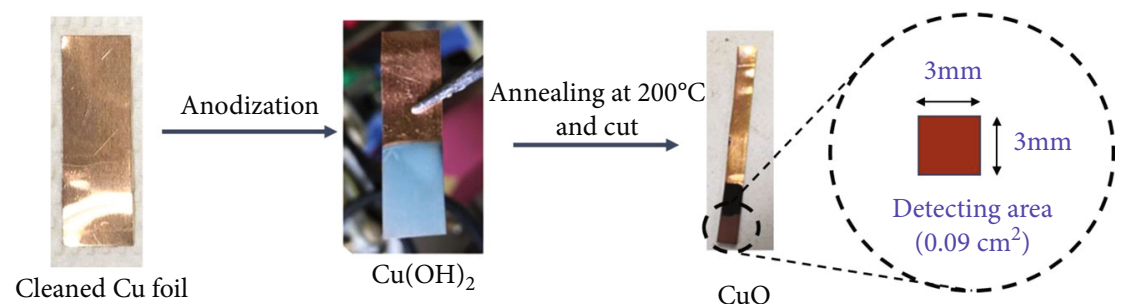

Figure 4: Image of electrode at each fabrication stage. The detection area of the electrode was $0.09 \mathrm{~cm}^{2}$.

Scanning electron microscopy (SEM; JEOL JSM-IT500HR) was used to observe the morphology and density of the nanostructure on the electrode's surface. Lastly, the chemical composition of the synthesized nanostructure on the $\mathrm{Cu}$ foil was confirmed by energy-dispersive X-ray spectroscopy (EDS).

\subsection{Electrochemical Measurements. Electrochemical proper-} ties of fabricated electrodes were evaluated by performing $\mathrm{CV}$ in $5 \mathrm{~mL}$ of $0.25 \mathrm{M} \mathrm{NaOH}$ solution where the applied potentials were varied from -1.5 to $0.5 \mathrm{~V}$ at a scan rate of $50 \mathrm{mV} / \mathrm{s}[41,42]$. The CV analysis was performed using Autolab PGSTAT101. After the CV voltage scan, a working potential (i.e., low potential with high redox activity) was selected as a reference position to observe the current change $(\Delta I)$ for quantitative analysis. The optimized electrodes were then applied for the OPP analysis. The CV was then performed in the same setup as above to individually detect the four OPPs (chlorpyrifos, pirimiphos, parathion, and 


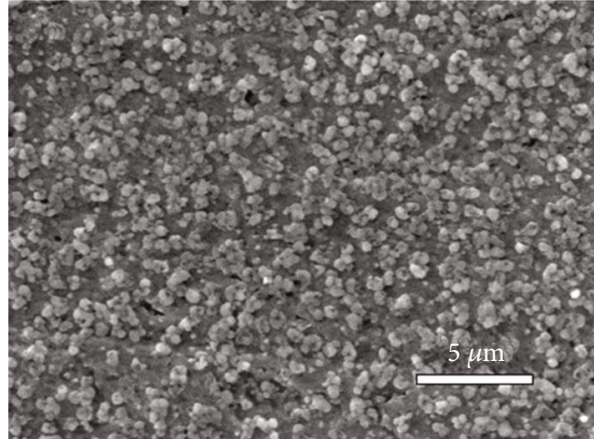

(a)

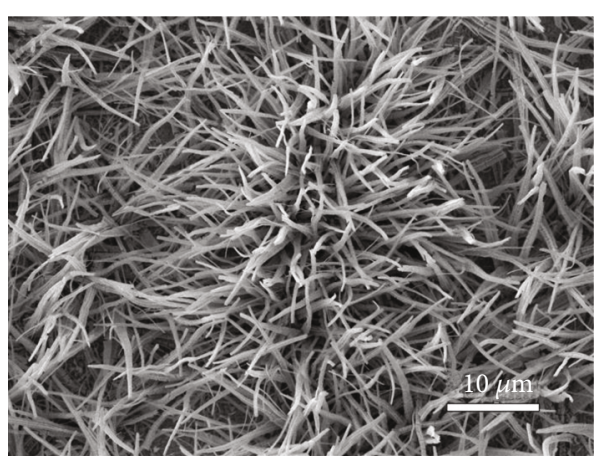

(b)

FIgURE 5: Representative SEM images of the (a) acid-washed $\mathrm{Cu}$ foil and (b) CuO NRs covering the surface of the Cu foil after anodization.

paraoxon). Similar experiments were performed using the interference analytes (i.e., carbaryl, paraquat, sodium nitrate, sodium sulphate, and toluene) to verify the selectivity of the $\mathrm{CuO}$ NR electrode. All analytes were prepared and injected into $0.25 \mathrm{M} \mathrm{NaOH}$ solution separately at different concentrations $(0.5,2,50,100,200,700,1200$, and $2000 \mathrm{ng} / \mathrm{mL})$ and left for $2 \mathrm{~min}$ before conducting the $\mathrm{CV}$ measurement. Finally, the change in current at different concentrations of each pesticide was investigated at a certain reference potential and plotted as a calibration curve.

\section{Results and Discussion}

3.1. Morphology and Composition Analysis. Representative SEM images of the $\mathrm{Cu}$ foil before and after anodization in $3 \mathrm{M} \mathrm{KOH}$ at a constant current density are shown in Figure 5. The acid-washed $\mathrm{Cu}$ foil exhibited copper nucleation on the surface as small particulates. The nanoparticles were homogeneously distributed on the surface with a diameter of $200-500 \mathrm{~nm}$ and served as the template for the $\mathrm{CuO}$ NR's growth. After anodization and annealing of the $\mathrm{Cu}$ foil, densely packed NR arrays were clearly visible. The NRs had a solid curved structure, and the diameter of the rods decreased from the base to the tip. The obtained NRs possessed a high aspect ratio with an average length of several microns, where the diameter at their bases was slightly larger than the diameter of the NPs before anodization. Elemental analysis showed the apparent increase in the oxygen percentage from $7.01 \pm 0.04 \%$ to $16.47 \pm 0.06 \%$, which indicated the formation of the $\mathrm{CuO}$ NR structures the after anodization process. In addition, the EDS result presented only $\mathrm{Cu}$ and oxygen atoms on these samples and so demonstrated the high purity of the fabrication process.

The morphology of the fabricated CuO NRs after anodization for 15, 20, 25, and 30 min was investigated by SEM and is illustrated in Figure 6 at a magnification of $\times 2000, \times 5000$, $\times 10000$, and $\times 20000$. The NR arrays were uniformly distributed and densely covered the $\mathrm{Cu}$ foil surface in all the samples, as seen in the low-resolution SEM images. The detailed morphology of the NR arrays was similar at all anodization times, in which the curvy NR's diameter gradually decreased from the base to the tip. However, NRs anodized for a longer time demonstrated larger diameters and longer lengths, whereas shorter anodization times resulted in smaller but more concentrated $\mathrm{CuO}$ NRs per area. The average length of the $\mathrm{CuO}$ NRs was observed as 3, 5, 8, and $12 \mathrm{~nm}$ after anodization for $15,20,25$, and $30 \mathrm{~min}$, respectively, whereas the average diameters of the tips of the $\mathrm{CuO}$ NRs were $80,200,370,500 \mathrm{~nm}$, respectively. This result explained well the increasing growth of the NR structure with increasing anodization time. However, side fragments were initiated on the $\mathrm{CuO}$ NRs at longer anodization times (25 and $30 \mathrm{~min}$ ), as seen in the SEM images at $\times 20000$.

The XRD patterns for the different samples (Figure 7) were used to identify the phase composition of the surfacemodified electrodes. The XRD patterns revealed a combination of $\mathrm{Cu}, \mathrm{CuO}$, and $\mathrm{Cu}_{2} \mathrm{O}$. The dominant peaks, labelled with an asterisk, represented the diffraction lines of the $\mathrm{Cu}$ foil substrate. The diffraction peaks at a $2 \theta$ of 29.6 (110), 42.3 (200), 61.5 (220), and 74.1 (311) corresponded to the crystalline $\mathrm{Cu}_{2} \mathrm{O}$ (JCPDS 78-2076), while the peaks at a $2 \theta$ of 35.5 (002) and 38.7 (111) belong to the $\mathrm{CuO}$ crystal structure (JCPDS 80-1917) [43]. All electrodes exhibited similar XRD patterns, where the dominant plane in all the samples was the (200) of $\mathrm{Cu}$, since the background $\mathrm{Cu}$ foil substrate was predominant compared with the synthesized metal oxides/hydroxide. The crystal planes of the desired $\mathrm{CuO}$ were only observed in the electrodes anodized for 20, 25, and $30 \mathrm{~min}$. These long-time anodization samples successfully created the $\mathrm{CuO}$ NR structure. However, the $15 \mathrm{~min}$ anodized sample did not exhibit any peak of $\mathrm{CuO}$, but rather the prominent $\mathrm{Cu}_{2} \mathrm{O}$ peaks suggested the incomplete oxidation of the electrode. It could not create the higher oxidation $\mathrm{CuO}$ for the ligand's coordination, unlike the electrodes derived from prolonged anodization times.

3.2. Electrochemical Analysis. The CV curves of the bare $\mathrm{Cu}$ and anodized $\mathrm{Cu}$ foil at different conditions are compared in Figure 8(a). All samples demonstrated the four characteristic peaks of a $\mathrm{Cu}$ electrode in $0.25 \mathrm{M} \mathrm{NaOH}$ [39], namely, two oxidation peaks (at $-0.37 \mathrm{~V}$ and $0.05 \mathrm{~V}$ ) and two reduction peaks (at $-0.56 \mathrm{~V}$ and $-0.92 \mathrm{~V}$ ). A low working potential and high current peak are desirable for a sensor application, and so, the potential of the second oxidation peak was selected for quantitative analysis. The current magnitude of the anodized $\mathrm{CuO}$ NRs revealed a large enhancement by 15 - to 20-fold compared to the bare $\mathrm{Cu}$ foil at $0.05 \mathrm{~V}$. Prolonged anodization led to more $\mathrm{CuO}$ crystallization, and as 

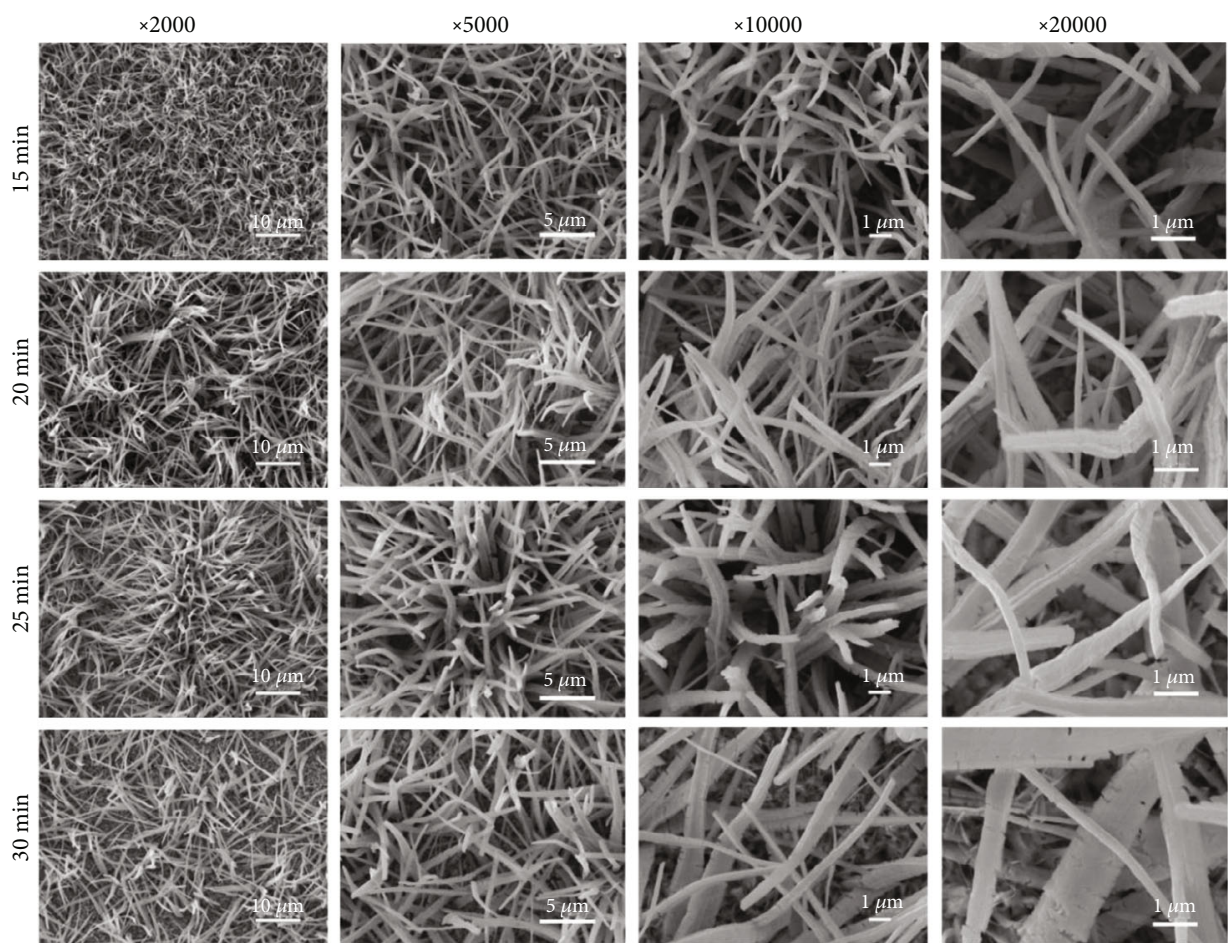

FIgURE 6: Representative SEM images $(\times 2000, \times 5000, \times 10,000$, and $\times 20,000)$ of the CuO NRs formed on the Cu foil surface after different anodization times $(15,20,25$, and $30 \mathrm{~min})$.
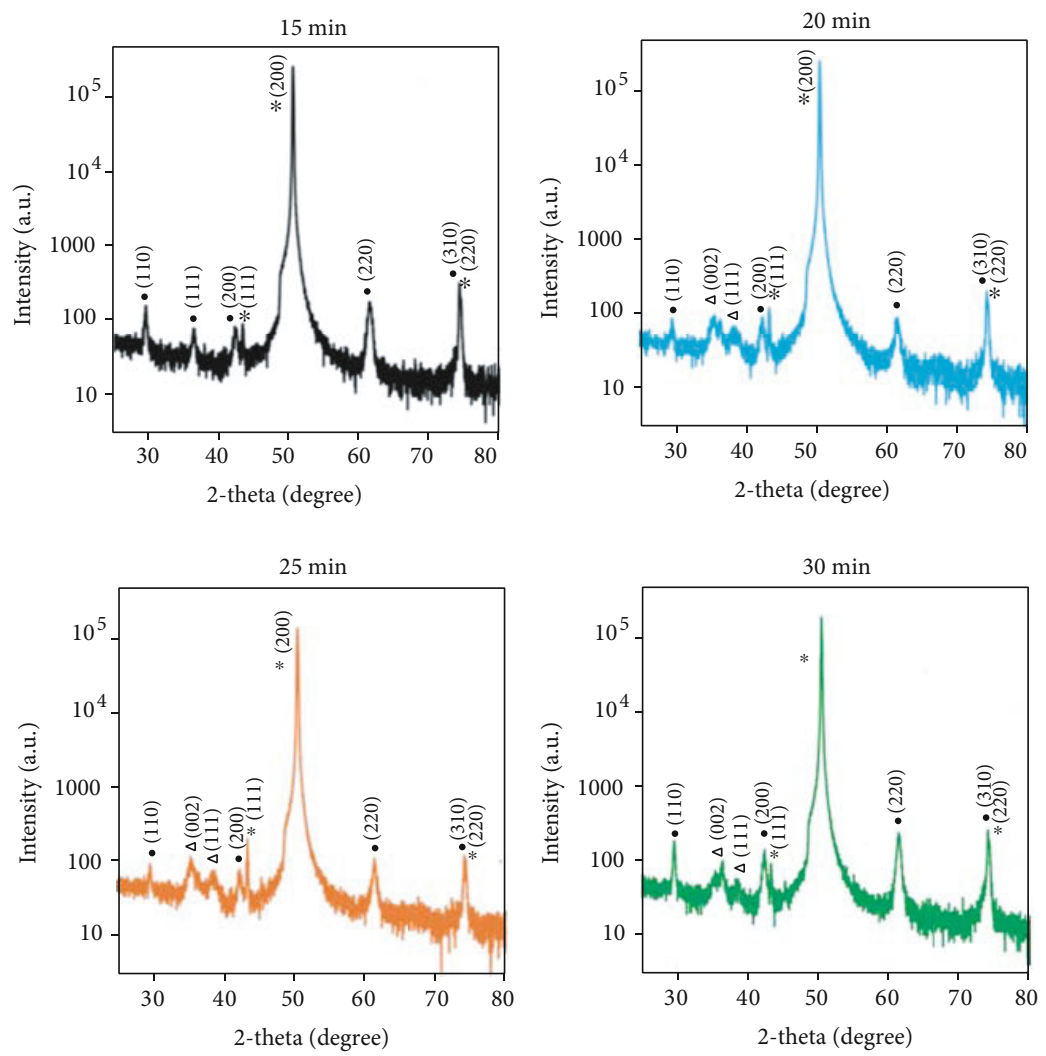

$$
\begin{aligned}
& \text { - } \mathrm{Cu}_{2} \mathrm{O} \\
& \triangle \mathrm{CuO} \\
& * \mathrm{Cu}
\end{aligned}
$$

FIgURE 7: Representative XRD patterns of the $\mathrm{Cu}$ foil electrode after being anodized for 15, 20, 25, and $30 \mathrm{~min}$. 


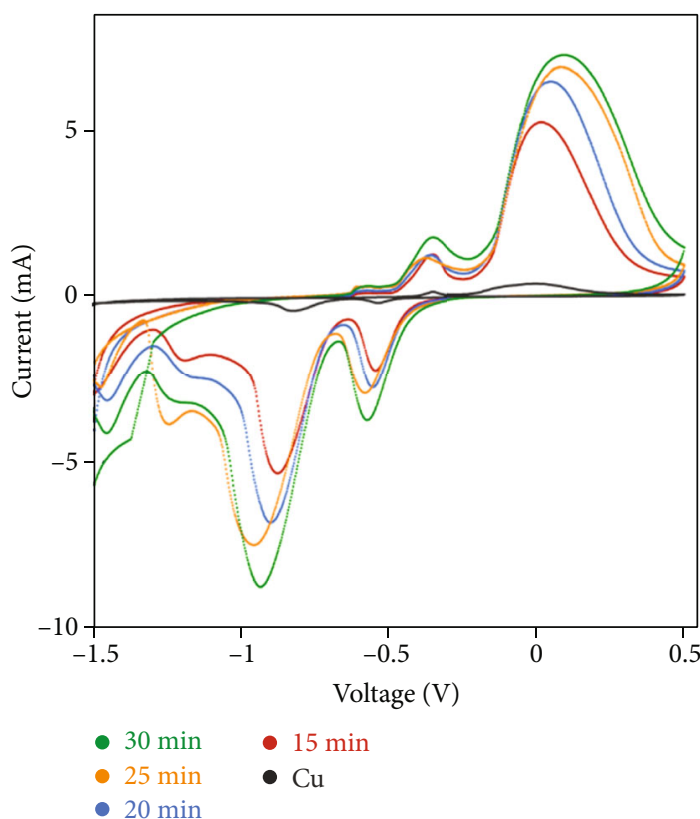

(a)

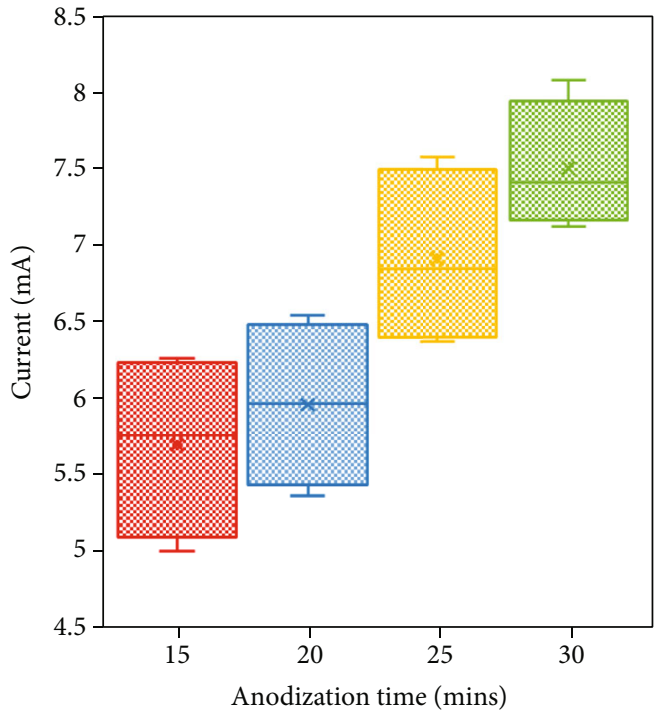

(b)

FIgURE 8: (a) Representative cyclic voltammograms of the CuO NR electrode anodized for 15, 20, 25, and $30 \mathrm{~min}$ in $0.25 \mathrm{M} \mathrm{NaOH}$ over a potential range from -1.5 to $0.5 \mathrm{~V}$ at a scan rate of $50 \mathrm{mV} / \mathrm{s}$. (b) Box plots of the peak current distribution from the $\mathrm{CV}$ results of the CuO NR electrodes anodized for $15,20,25$, and $30 \mathrm{~min}$.

a result, the electrochemical reaction exhibited a higher current peak. On the other hand, the samples anodized for 15 min did not have a detectable crystalized $\mathrm{CuO}$ pattern in the XRD analysis, resulting in the least enhancement of the electrochemical reaction. The longer anodization times (20, 25 , and $30 \mathrm{~min}$ ) largely resulted in a higher current peak, but the difference between them decreased with increasing anodization time and was predictively saturated after 30 min anodization. This was potentially caused by the formation of tiny cracks along the NR surface with increasing anodization times. Thus, the anodization time was already optimized at around $30 \mathrm{~min}$ with a distinguished electrochemical characteristic.

For each anodization time $(15,20,25$, and $30 \mathrm{~min})$, four electrodes derived from a similar fabrication method were investigated in $0.25 \mathrm{M} \mathrm{NaOH}$. Figure $8(\mathrm{~b})$ presents the box plots of the peak currents for the electrodes derived from the four different anodization times. The relative standard deviation (RSD) for the different anodization times was $10.77 \%, 9.30 \%, 8.91 \%$, and $5.54 \%$ for a $15,20,25$, and $30 \mathrm{~min}$ anodization time, respectively, indicating a better reproducibility and stability with increasing anodization time over the examined range (15-30 $\mathrm{min}$ ).

The electrochemical analysis of the $\mathrm{CuO}$ NRs towards different analytes (chlorpyrifos, pirimiphos, parathion, paraoxon, carbaryl, paraquat, toluene, sodium sulphate, and sodium nitrate) at varying concentrations $(0,0.5,1,2,50$, $100,200,700,1000$, and $2000 \mathrm{ng} / \mathrm{mL}$ ) was conducted by performing $\mathrm{CV}$ in $0.25 \mathrm{M} \mathrm{NaOH}$ (Figure 9). The $\mathrm{CV}$ results of all the analytes were evaluated for the inter- and intra-assay precision over 10 cycles with three electrodes each. The RSDs of the inter- and intra-assays were found to be $6.5 \%$ and $2.6 \%$, respectively. Although the intra-assay RSDs showed an acceptable reproducibility, the variation among individual electrodes could have been caused by human error during fabrication. The addition of pesticides instigated a drop in the current peak from the $\mathrm{NaOH}$ redox (at $0 \mathrm{ng} / \mathrm{mL}$ of analytes) by inhibition activity. The ligands on the pesticide molecules feasibly chelated the $\mathrm{Cu}$ atoms on the $\mathrm{CuO} \mathrm{NR}$ electrodes and so caused a reduced electron transfer. The pesticide molecules coordinated on the $\mathrm{CuO}$ electrodes prevented the charge transfer in the redox reaction. All analytes showed a concentration-dependent decreased current peak with a different inhibition rate, except for sodium sulphate and sodium nitrate that demonstrated an increased redox current at higher concentrations.

For the quantitative analysis, the change in current $(\Delta I)$ with respect to the reference ( $I_{0}$ - current of blank solution) electrode at the second oxidation peak $(V=0.05 \mathrm{~V})$ was determined and plotted as a calibration curve. The regression analysis of the analytes was presented as the relationship between the $\%$ current change $\left(|\Delta I| / I_{0}\right)$ vs. analyte concentration. Figure 10(a) presents the results for the potentially inhibitory analytes, where the current decreased with higher analyte concentrations $(\Delta I<0)$, including all the pesticides and toluene. Analytes with a current induction mechanism (i.e., sodium sulphate and sodium nitrate) gave a higher current at higher concentrations $(\Delta I>0)$, as seen in Figure 10(b). All OPPs exhibited a linear inhibition trend with different sensitivities.

However, carbaryl and paraquat, which belong to carbamate insecticides and bipyridyl herbicides, respectively, demonstrated a nonlinear relationship. These two non-OPPs do not possess a phosphate group on the molecules. Carbaryl 

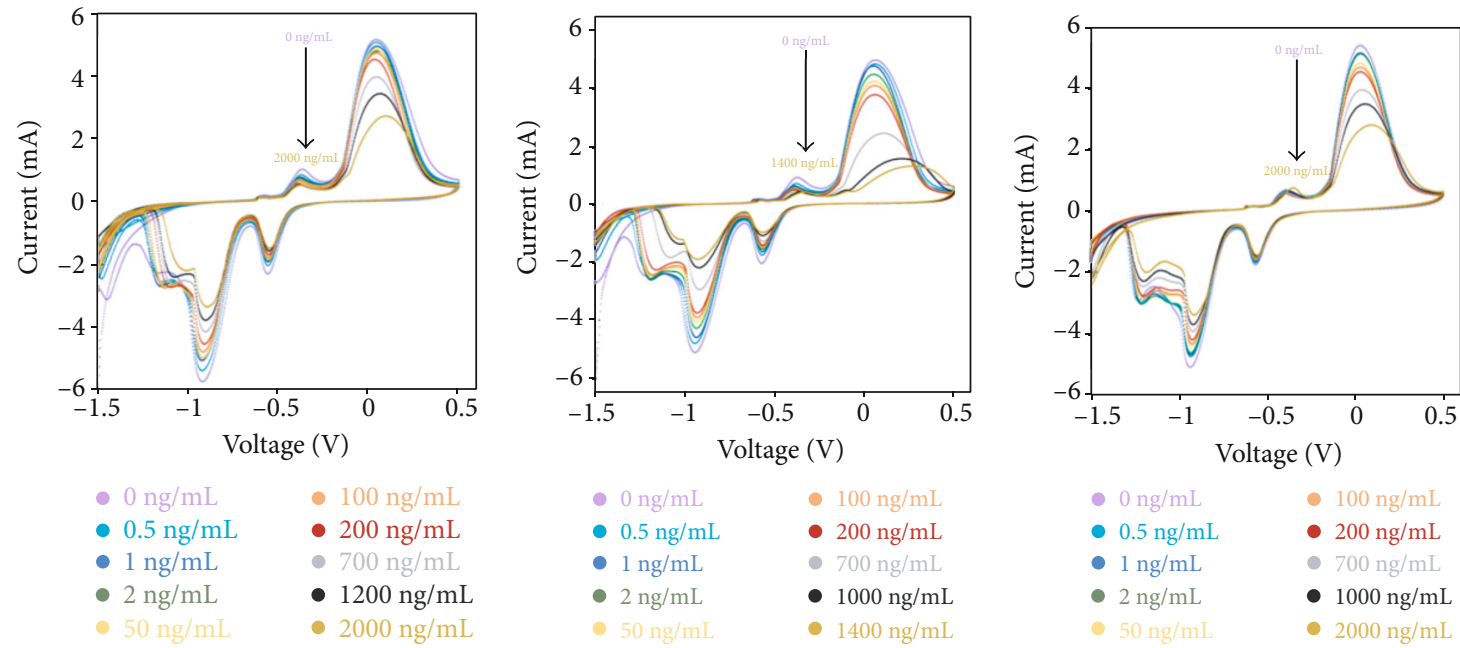

(b)
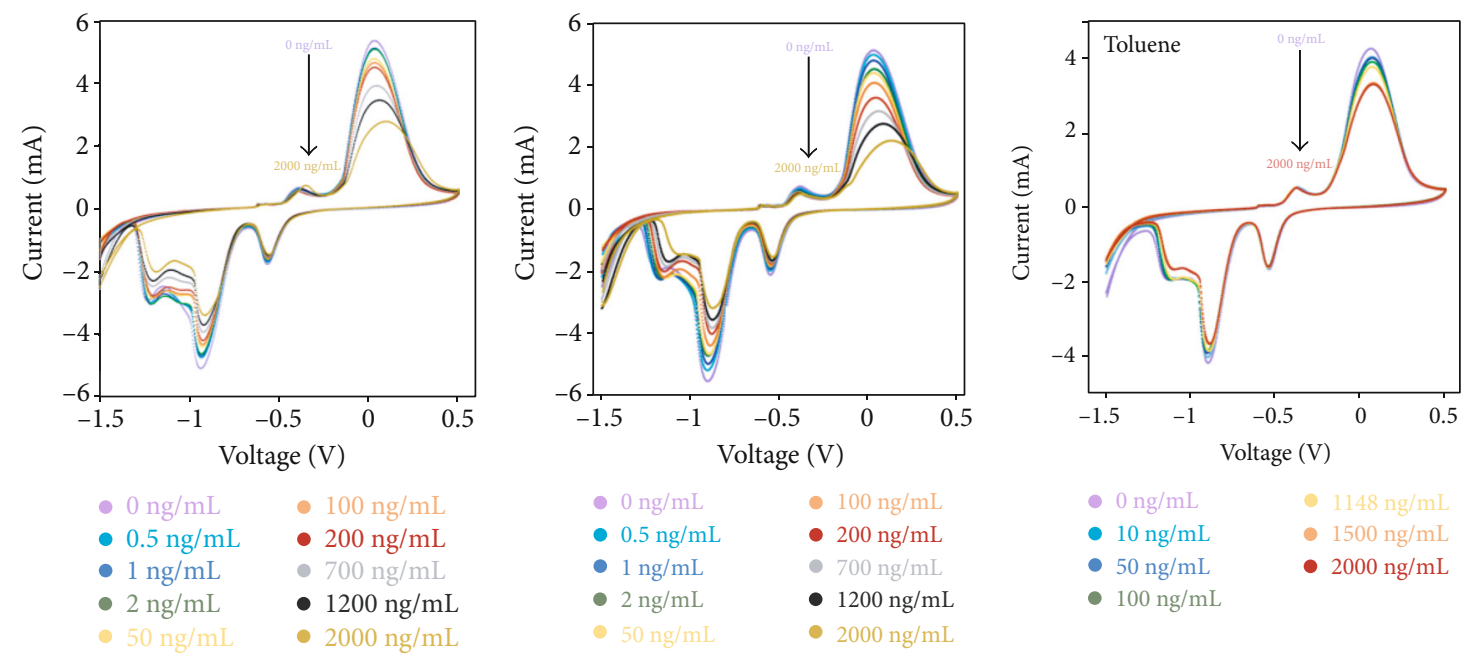

(d)
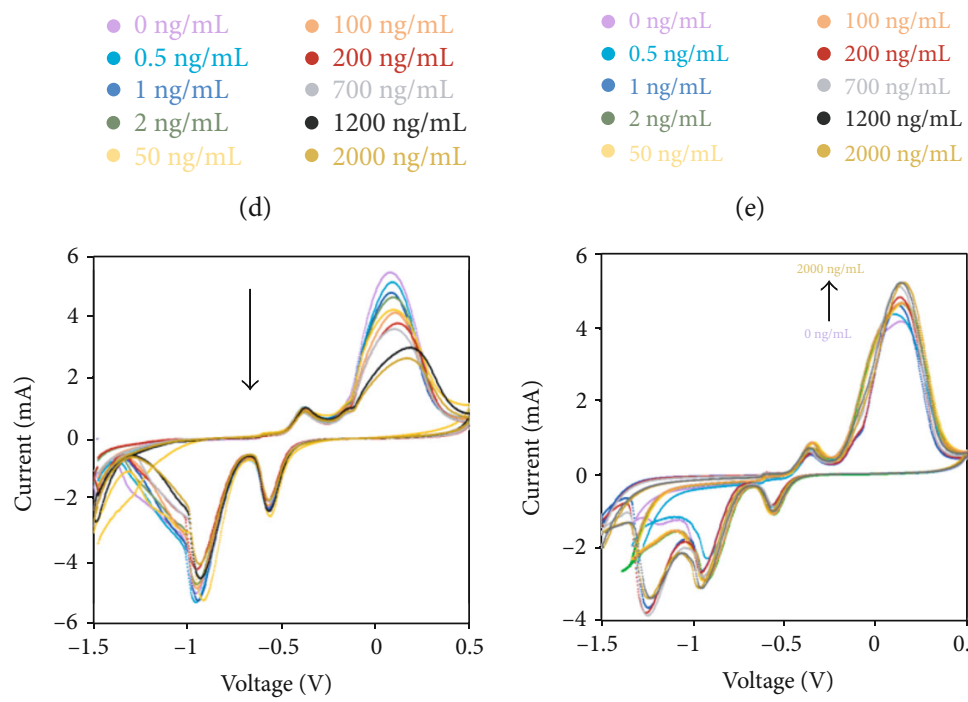

(e)

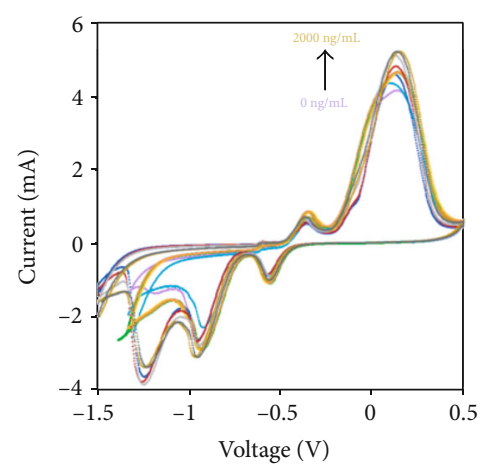

(f)
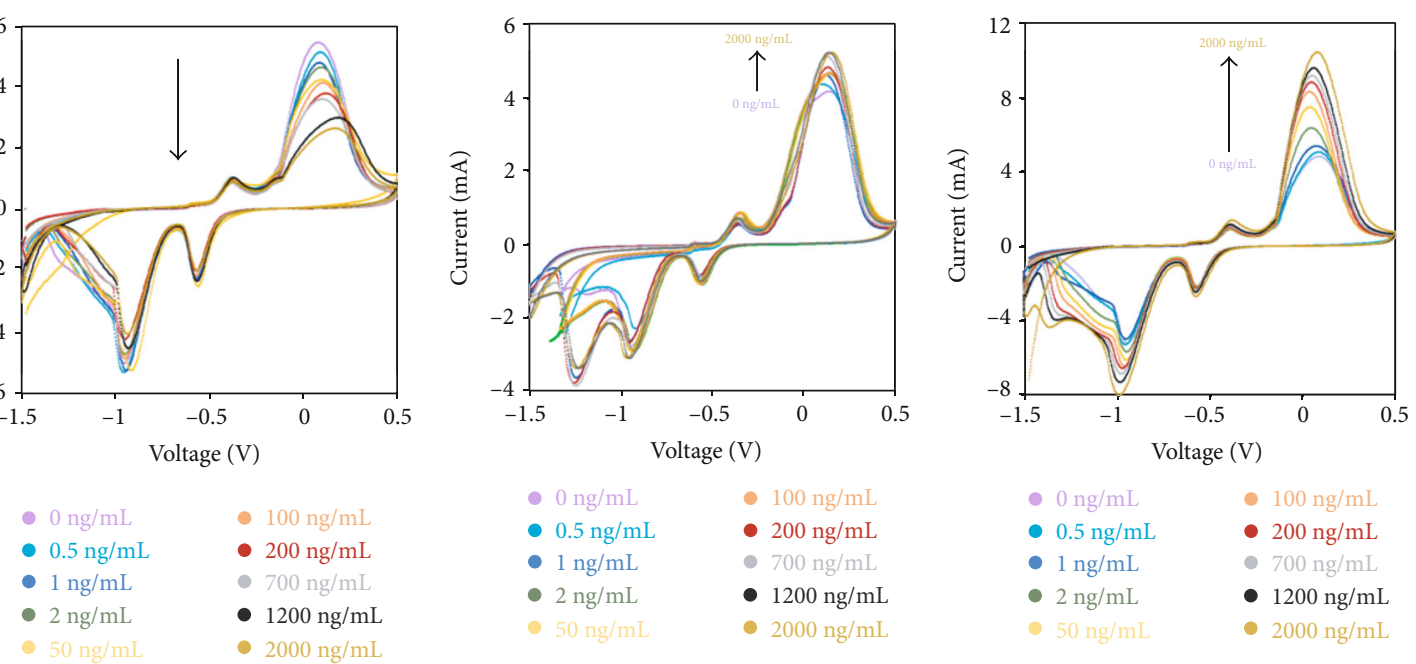

(h)

(g)

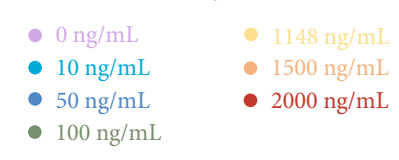

Figure 9: Representative cyclic voltammograms of the CuO NRs in $0.25 \mathrm{M} \mathrm{NaOH}$ solution at different concentrations $(0,0.5,1,2,50,100$, 200, 700, 1000, and $2000 \mathrm{ng} / \mathrm{mL}$ ) of (a) chlorpyrifos, (b) pirimiphos, (c) parathion, (d) paraoxon, (e) carbaryl, (f) toluene, (g) paraquat, (h) sodium sulphate, and (i) sodium nitrate analytes. 


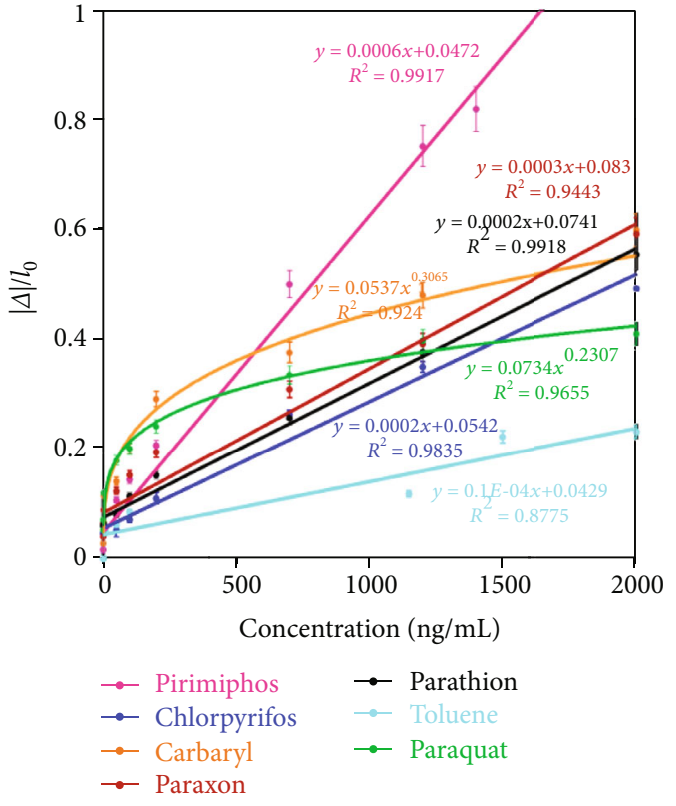

(a)

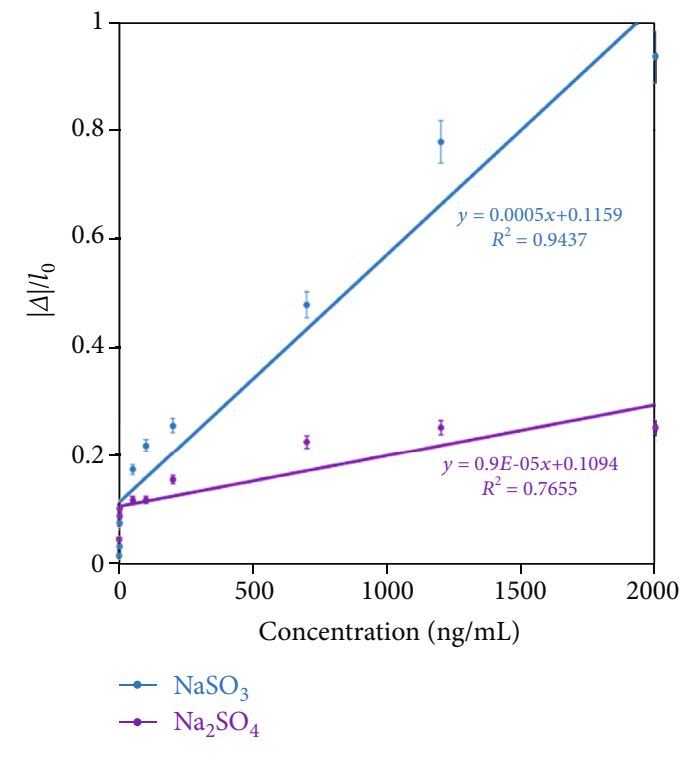

(b)

Figure 10: (a) Calibration curves of the $\mathrm{CuO}$ NR electrode in response to different current inhibition samples (chlorpyrifos, pirimiphos, parathion and paraoxon, carbaryl, paraquat, and toluene). (b) Calibration curves of the $\mathrm{CuO}$ NR electrode in response to current induction samples (sodium sulphate and sodium nitrate). In both panels, the data are shown as the mean \pm 1 standard deviation of CV measurements for 10 cycles with three electrodes per run $(n=30)$.

showed a drastic drop in the current at a low concentration, while it was saturated at an elevated concentration. The large amount of naphthalene ligands available at a high concentration of carbaryl caused $\pi$-stacking among the benzene rings rather than protrude through the electrode surface and coordinate with electrodes. Similarly, paraquat, with double carbon rings, showed a drastic drop in the initial current at low concentrations and was saturated at a high concentration. However, paraquat contains two pyridinium ions $\left[\mathrm{C}_{5} \mathrm{H}_{6} \mathrm{~N}^{+}\right]$that are considered to be a strong field ligand and require higher energy to coordinate with the $\mathrm{Cu}$ electrodes and so give less current inhibition. These two nonOPPs could easily be excluded from the other OPPs as they presented a nonlinear trend.

Toluene did not exhibit any current reduction unless at a very high concentration $(>1000 \mathrm{ng} / \mathrm{mL})$. There is no potential ligand on the toluene molecule to interact with $\mathrm{Cu}^{2+}$ atoms, and so, the current drop induced by toluene was not directly caused by a coordination bond with the electrode, but rather at a high concentration, the molecules themselves overwhelmed the surface of the electrodes, retarding electron transfer. Sodium sulphate is another kind of electrolyte that induced a higher oxidation current when added at higher concentrations, but the concentration was too low (micromolar level) to compete with the effect from the $\mathrm{NaOH}$ solution. We only observed a weak relationship with changes in the sulphate solution concentration (Figure 9(b)), whereas sodium nitrate presented a higher current inductive effect than the sulphate solution. Sodium nitrate could react to form an acidic solution of copper nitrate and directly lead to the formation of $\mathrm{Cu}(\mathrm{OH})_{2}$ on the electrodes when reacting with $\mathrm{NaOH}$. These reactions could further modify the electrode surface, and as a result, the oxidation current increased in the CV response. These two interferences demonstrated a current induction mechanism rather than inhibition, and so, they would not be of concern for selectivity analysis with OPPs.

The sensitivity of each OPP detection was obtained from the linear regression of the relative current blockage $\left(\Delta I / I_{0}\right)$ against the concentration of analytes. The limit of detection (LOD) was calculated from the three-sigma approach; LOD $=3 * \mathrm{SD} / S_{\text {avg }}$, where $\mathrm{SD}$ is the standard deviation of the blank measurement and $S_{\text {avg }}$ is the average sensitivity of each analyte. The obtained sensitivity and LOD for each sample are listed in Table 1. The obtained sensitivity of the $\mathrm{CuO}$ NRs was $1.269,1.425,1.657$, and $2.833 \mu \mathrm{A} / \mathrm{ng} \mathrm{mL}^{-1}$ for chlorpyrifos, parathion, paraoxon, and pirimiphos, respectively. The LOD of all analytes was in agreement with the sensitivity analysis, where the analyte with a better sensitivity could be detected at a lower LOD. The lowest LOD in this study was $0.294 \mu \mathrm{M}$ of pirimiphos with the best sensitivity of $2.833 \mu \mathrm{A} / \mathrm{ng} \mathrm{mL}^{-1}$.

Despite all the tested OPPs having a mutual functional group (phosphothionate or phosphate), the $\mathrm{CuO}$ NR electrode was most sensitive towards pirimiphos and had a different sensitivity for all the OPPs. This result demonstrated a great selectivity towards each OPP, which is not achieved with the enzyme-based sensor. Table 1 presents a comparison between the LOD maximum residue limit (MRL) of pesticides in foods (European legislation) and the MRL of pesticides in water (IUPAC Technical Report) [44]. Our sensor showed the ability to detect pirimiphos, paraoxon, and parathion 
TABLE 1: The LOD and sensitivity of the CuO NR electrode for different types of OPPs and toluene.

\begin{tabular}{lcccccc}
\hline Analytes & $\begin{array}{c}\text { Coefficient of } \\
\text { determination }\left(R^{2}\right)\end{array}$ & $\begin{array}{c}\text { Sensitivity } \\
\left(\mu \mathrm{A} / \mathrm{ng} \mathrm{mL}^{-1}\right)\end{array}$ & $\begin{array}{c}\text { Detection } \\
\text { limit }(\mu \mathrm{M})\end{array}$ & $\begin{array}{c}\text { LOD }(\mathrm{mg} / \mathrm{L} \text { or } \\
\mathrm{mg} / \mathrm{kg} \text {-water })\end{array}$ & $\begin{array}{c}\text { MRL of pesticide } \\
\text { in water }(\mathrm{mg} / \mathrm{L})\end{array}$ & $\begin{array}{c}\text { MRLs in food from EU Pesticides } \\
\text { Database (v2.1) }(\mathrm{mg} / \mathrm{kg})\end{array}$ \\
\hline Pirimiphos & 0.988 & $2.833 \pm 0.622$ & $0.294 \pm 0.012$ & 0.09 & $0.1^{*}$ & $0.01-5(\mathrm{Reg}$. (EU) No. 2016/53) \\
Paraoxon & 0.961 & $1.657 \pm 0.106$ & $0.557 \pm 0.020$ & 0.15 & $0.05^{*}$ & $0.01-5(\mathrm{Reg}$. (EU) No. 899/2012) \\
Parathion & 0.876 & $1.425 \pm 0.276$ & $0.612 \pm 0.118$ & 0.18 & $0.05^{*}$ & $0.01-5$ (Reg. (EU) No. 899/2012) \\
Chlorpyrifos & 0.976 & $1.269 \pm 0.245$ & $0.571 \pm 0.063$ & 0.20 & $0.07^{*}$ & 0.01 (Reg. (EU) 2020/1085) \\
\hline
\end{tabular}

${ }^{*}$ Data from regulatory limits for pesticide residues in water (IUPAC Technical Report) [44].

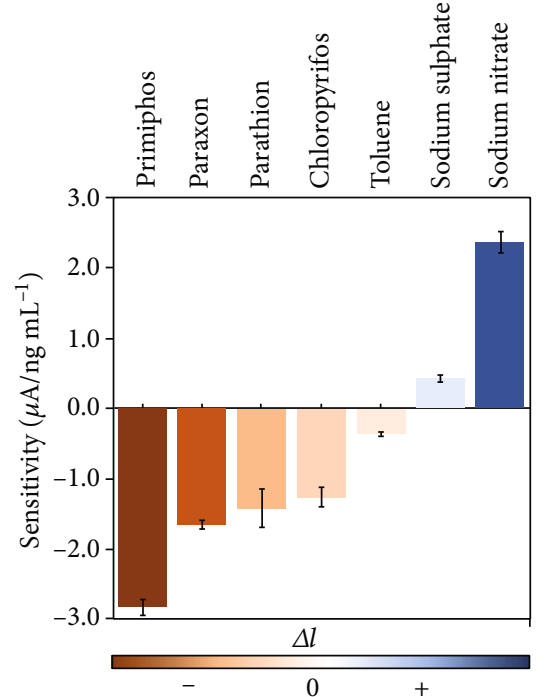

FIgure 11: Comparison of the sensitivity of the $\mathrm{CuO}$ NR electrode towards different OPPs, toluene, sodium sulphate, and sodium nitrate. Data are shown as the mean $\pm 1 \mathrm{SD}$, derived from $\mathrm{CV}$ measurements over 10 cycles with three electrodes per run $(n=30)$.

within the MRL range of food samples. However, chlorpyrifos was just globally banned worldwide in 2020, and the MRL of all foods cannot exceed $0.01 \mathrm{mg} / \mathrm{kg}$. This level could not be reached by the LOD of our sensor for chlorpyrifos. For sample analysis in water, our sensor could demonstrate the ability to detect MRL of pirimiphos in drinking water.

The distinct sensitivity towards different OPs caused by other ligand molecules (e.g., the trichloro pyridine of chlorpyrifos, pyrimidine of pirimiphos, and nitrobenzene of parathion and paraoxon) that compete or assist with the oxonate or thionate group to coordinate with the $\mathrm{Cu}^{2+}$ atom corresponds to the different affinities towards different pesticide molecules. The triethylamine, a Lewis base, of pirimiphos has a high affinity towards metal coordination by donating electron lone pairs and hence has the best sensitivity, whereas both parathion and paraoxon, which possess nitrobenzene, showed almost the same sensitivity of detection. The ligand of trichloro pyridine of chlorpyrifos had a low affinity towards $\mathrm{Cu}^{2+}$, and so, it showed the lowest sensitivity among all the OPPs.

The selectivity of an OPP towards the $\mathrm{CuO}$ NR sensor mainly came from the distinct functional group(s) on the molecules. The evidence of different complex formations for different kinds of molecules was present in the UV-vis spectroscopy (Figure S1), where different coordination bonds were formed when $\mathrm{Cu}^{2+}$ binds to different functional groups on each (pesticide) molecule. Each $\mathrm{Cu}^{2+}$-pesticide complex exhibited a different spectrum pattern with the peaks being located differently, except for parathion and paraoxon that showed very similar spectra. These UV spectroscopy results were in agreement with the electrochemical analysis of the pesticides.

The selectivity for the different analytes is shown in Figure 11. Note that since carbaryl and paraquat had a nonlinear relationship with their concentration, they were excluded from this selectivity consideration. The inhibition analytes presented a negative $\Delta I$ (red colour), whereas inductive interference showed a positive $\Delta I$ (blue colour). The magnitude of the current change is visualized as changes in the shaded colour from red (-) to blue (+). The $\mathrm{CuO} \mathrm{NR}$ electrodes delivered the ability to qualify and quantify different pesticides and to explicitly separate them from the interference molecules. The performance of this $\mathrm{CuO}$ NR sensor compared with other works is compared in Table S1. The CuO NR sensor of this study had a LOD for the tested OPPs that ranged from 0.29 to $0.61 \mu \mathrm{M}$, showing a competitive range of detection compared to the other previously reported pesticide sensors (Table S1).

\section{Conclusions}

The $\mathrm{CuO}$ NR electrode gave a desirable electrocatalytic performance and strong affinity towards each OPP. Besides, OPPs can be excluded from interference with ease in this work. In the future, other groups of pesticides and interferences will be tested to further justify the selectivity of this $\mathrm{CuO}$ NR pesticide sensor. At present, it exhibited a better selectiveness than the enzymatic sensor, which cannot differentiate among OPPs. Electrochemical results demonstrated a linear regression between the current and the OPP concentration, which can be used to quantify unknown samples in future implementation. The fabricated electrodes achieved very low LODs for OPPs, in the range of $0.29-0.61 \mu \mathrm{M}$, compared to the other reported OPP sensors.

At this level, it can be applied to determine the MRL of each pesticide in foods. Subsequently, the sensor will further be applied in real vegetable samples as it presents the ability to quantify OPPs at minute amounts that approach the MRL. Moreover, because of its high stability and ease of preparation, this sensor could potentially be integrated with a portable potentiostat for on-site and wearable device application. 


\section{Data Availability}

The datasets generated during the current study are available from the corresponding author on request.

\section{Conflicts of Interest}

The authors declare that there is no conflict of interest regarding the publication of this paper.

\section{Acknowledgments}

The Biochemical Engineering laboratory and National Metal and Materials Technology Center (MTEC) are gratefully acknowledged for the facilities to perform this work. This research was funded by a Chulalongkorn University Research Grant (Rachadapiseksompoj Grant), grant number CU_GR_63_37_21_05, and Digital Economy and Society Development Funds (ONDE), grant number PR63031761.

\section{Supplementary Materials}

include UV-vis spectroscopy of complex product between $\mathrm{CuO} \mathrm{NR}$ electrodes and four pesticides and the table of detection limit comparison between other literatures and this work. (Supplementary Materials)

\section{References}

[1] D. Z. Hung, H. J. Yang, Y. F. Li et al., "The long-term effects of organophosphates poisoning as a risk factor of CVDs: a nationwide population-based cohort study," PLoS One, vol. 10, no. 9, pp. e0137632-e0137632, 2015.

[2] M. Jokanović, "Neurotoxic effects of organophosphorus pesticides and possible association with neurodegenerative diseases in man: a review," Toxicology, vol. 410, pp. 125-131, 2018.

[3] M. T. Muñoz-Quezada, B. A. Lucero, V. P. Iglesias et al., "Chronic exposure to organophosphate (OP) pesticides and neuropsychological functioning in farm workers: a review," International Journal of Occupational and Environmental Health, vol. 22, no. 1, pp. 68-79, 2016.

[4] P. Nicolopoulou-Stamati, S. Maipas, C. Kotampasi, P. Stamatis, and L. Hens, "Chemical pesticides and human health: the urgent need for a new concept in agriculture," Frontiers in Public Health, vol. 4, no. 148, 2016.

[5] E.-m. An and H.-S. Shin, "Gas chromatographic determination of pesticide residues using electron-capture detector and mass spectrometry," Food Science and Biotechnology, vol. 20, no. 5, p. 1299, 2011.

[6] S. Walorczyk, I. Kopeć, and E. Szpyrka, "Pesticide residue determination by gas chromatography-tandem mass spectrometry as applied to food safety assessment on the example of some fruiting vegetables," Food Analytical Methods, vol. 9, no. 5, pp. 1155-1172, 2016.

[7] K. Seebunrueng, Y. Santaladchaiyakit, and S. Srijaranai, "Vortex-assisted low density solvent based demulsified dispersive liquid-liquid microextraction and high-performance liquid chromatography for the determination of organophosphorus pesticides in water samples," Chemosphere, vol. 103, pp. 5158,2014
[8] W. Ahmad, A. A. Al-Sibaai, A. S. Bashammakh, H. Alwael, and M. S. El-Shahawi, "Recent advances in dispersive liquid-liquid microextraction for pesticide analysis," TrAC Trends in Analytical Chemistry, vol. 72, pp. 181-192, 2015.

[9] H. V. Botitsi, S. D. Garbis, A. Economou, and D. F. Tsipi, "Current mass spectrometry strategies for the analysis of pesticides and their metabolites in food and water matrices," Mass Spectrometry Reviews, vol. 30, no. 5, pp. 907-939, 2011.

[10] A. Stachniuk and E. Fornal, "Liquid chromatography-mass spectrometry in the analysis of pesticide residues in food," Food Analytical Methods, vol. 9, no. 6, pp. 1654-1665, 2016.

[11] P.-L. Chang, M.-M. Hsieh, and T.-C. Chiu, "Recent advances in the determination of pesticides in environmental samples by capillary electrophoresis," International Journal of Environmental Research and Public Halth, vol. 13, no. 4, pp. 409-409, 2016.

[12] J. S. Noori, J. Mortensen, and A. Geto, "Recent development on the electrochemical detection of selected pesticides: a focused review," Sensors, vol. 20, no. 8, p. 2221, 2020.

[13] J. Shu and D. Tang, "Recent advances in photoelectrochemical sensing: from engineered photoactive materials to sensing devices and detection modes," Analytical Chemistry, vol. 92, no. 1, pp. 363-377, 2020.

[14] Q. Zhou and D. Tang, "Recent advances in photoelectrochemical biosensors for analysis of mycotoxins in food," $\operatorname{Tr} A C$ Trends in Analytical Chemistry, vol. 124, p. 115814, 2020.

[15] K. Zhang, S. Lv, Q. Zhou, and D. Tang, "CoOOH nanosheetscoated $\mathrm{g}-\mathrm{C}_{3} \mathrm{~N}_{4} / \mathrm{CuInS}$, nanohybrids for photoelectrochemical biosensor of carcinoembryonic antigen coupling hybridization chain reaction with etching reaction," Sensors and Actuators B: Chemical, vol. 307, p. 127631, 2020.

[16] N. Mionetto, J.-L. Marty, and I. Karube, “Acetylcholinesterase in organic solvents for the detection of pesticides: biosensor application," Biosensors and Bioelectronics, vol. 9, no. 6, pp. 463-470, 1994.

[17] A. Phongphut, B. Chayasombat, A. E. G. Cass et al., "Clay/au nanoparticle composites as acetylcholinesterase carriers and modified- electrode materials: a comparative study," Applied Clay Science, vol. 194, p. 105704, 2020.

[18] A. C. Ion, I. Ion, A. Culetu et al., "Acetylcholinesterase voltammetric biosensors based on carbon nanostructure- chitosan composite material for organophosphate pesticides," Materials Science and Engineering: C, vol. 30, no. 6, pp. 817$821,2010$.

[19] F. Febbraio, L. Merone, G. P. Cetrangolo, M. Rossi, R. Nucci, and G. Manco, "Thermostable esterase 2 from Alicyclobacillus acidocaldarius as biosensor for the detection of organophosphate pesticides," Analytical Chemistry, vol. 83, no. 5, pp. 1530-1536, 2011.

[20] N. Verma and A. Bhardwaj, "Biosensor technology for pesticides-a review," Applied Biochemistry and Biotechnology, vol. 175, no. 6, pp. 3093-3119, 2015.

[21] J. Kumar and S. F. D'Souza, "Microbial biosensor for detection of methyl parathion using screen printed carbon electrode and cyclic voltammetry," Biosensors and Bioelectronics, vol. 26, no. 11, pp. 4289-4293, 2011.

[22] T. Sikora, G. Istamboulie, E. Jubete, E. Ochoteco, J.-L. Marty, and T. Noguer, "Highly sensitive detection of organophosphate insecticides using biosensors based on genetically engineered acetylcholinesterase and poly(3,4-ethylenedioxythiophene)," Journal of Sensors, vol. 2011, Article ID 102827, 7 pages, 2011. 
[23] Y. Li, Y. Zhang, G. Han, Y. Xiao, M. Li, and W. Zhou, "An acetylcholinesterase biosensor based on graphene/polyaniline composite film for detection of pesticides," Chinese Journal of Chemistry, vol. 34, no. 1, pp. 82-88, 2016.

[24] B. Wang, C. Ye, X. Zhong, Y. Chai, S. Chen, and R. Yuan, "Electrochemical biosensor for organophosphate pesticides and huperzine-a detection based on Pd wormlike nanochains/graphitic carbon nitride nanocomposites and acetylcholinesterase," Electroanalysis, vol. 28, no. 2, pp. 304-311, 2016.

[25] A. Rhouati, M. Majdinasab, and A. Hayat, "A perspective on non-enzymatic electrochemical nanosensors for direct detection of pesticides," Current Opinion in Electrochemistry, vol. 11, pp. 12-18, 2018.

[26] J. Bao, C. Hou, Q. Dong et al., "ELP-OPH/BSA/TiO 2 nanofibers/c-MWCNTs based biosensor for sensitive and selective determination of _. _ $_{-}$-nitrophenyl substituted organophosphate pesticides in aqueous system," Biosensors and Bioelectronics, vol. 85, pp. 935-942, 2016.

[27] N. Karimian, H. Fakhri, S. Amidi, A. Hajian, F. Arduini, and H. Bagheri, "A novel sensing layer based on metal-organic framework UiO-66 modified with $\mathrm{TiO}_{2}$-graphene oxide: application to rapid, sensitive and simultaneous determination of paraoxon and chlorpyrifos," New Journal of Chemistry, vol. 43, no. 6, pp. 2600-2609, 2019.

[28] M. Khairy, H. A. Ayoub, and C. E. Banks, "Non-enzymatic electrochemical platform for parathion pesticide sensing based on nanometer-sized nickel oxide modified screen-printed electrodes," Food Chemistry, vol. 255, pp. 104-111, 2018.

[29] B. Song, W. Cao, and Y. Wang, "A methyl parathion electrochemical sensor based on Nano- $\mathrm{TiO}_{2}$, graphene composite film modified electrode," Fullerenes, Nanotubes, and Carbon Nanostructures, vol. 24, no. 7, pp. 435-440, 2016.

[30] Y. Xie, Y. Yu, L. Lu et al., "CuO nanoparticles decorated 3D graphene nanocomposite as non-enzymatic electrochemical sensing platform for malathion detection," Journal of Electroanalytical Chemistry, vol. 812, pp. 82-89, 2018.

[31] D. Rawtani, N. Khatri, S. Tyagi, and G. Pandey, "Nanotechnology-based recent approaches for sensing and remediation of pesticides," Journal of Environmental Management, vol. 206, pp. 749-762, 2018.

[32] Y. Liu, G. Wang, C. Li, Q. Zhou, M. Wang, and L. Yang, “A novel acetylcholinesterase biosensor based on carboxylic graphene coated with silver nanoparticles for pesticide detection," Materials Science and Engineering: C, vol. 35, pp. 253-258, 2014.

[33] P. A. Raymundo-Pereira, N. O. Gomes, F. M. Shimizu, S. A. S. Machado, and O. N. Oliveira, "Selective and sensitive multiplexed detection of pesticides in food samples using wearable, flexible glove-embedded non-enzymatic sensors," Chemical Engineering Journal, vol. 408, p. 127279, 2021.

[34] J. M. Smolen and A. T. Stone, "Divalent metal ion-catalyzed hydrolysis of phosphorothionate ester pesticides and their corresponding oxonates," Environmental Science \& Technology, vol. 31, no. 6, pp. 1664-1673, 1997.

[35] F. Pino, C. C. Mayorga-Martinez, and A. Merkoçi, "High-performance sensor based on copper oxide nanoparticles for dual detection of phenolic compounds and a pesticide," Electrochemistry Communications, vol. 71, pp. 33-37, 2016.

[36] N. Rongwaree, T. Watcharawittayakul, C. Sooksamphanwong et al., "A comparative molecular study between chlorpyriphos and parathion using $\mathrm{CuO}$ nanohair pesticide sensor," in International Conference on Nano/Micro Engineered and Molecular
System (IEEE-NEMS), pp. 316-319, San Diego, CA, USA, 2020.

[37] N. A. Choudhry, D. K. Kampouris, R. O. Kadara, N. Jenkinson, and C. E. Banks, "Next generation screen printed electrochemical platforms: non-enzymatic sensing of carbohydrates using copper(ii) oxide screen printed electrodes," Analytical Methods, vol. 1, no. 3, pp. 183-187, 2009.

[38] I. Zaafarany and H. Boller, "Electrochemical behavior of copper electrode in sodium hydroxide solutions," Current World Environment, vol. 4, no. 2, pp. 277-284, 2009.

[39] L. Xu, Q. Yang, X. Liu, J. Liu, and X. Sun, "One-dimensional copper oxide nanotube arrays: biosensors for glucose detection," RSC Advances, vol. 4, no. 3, pp. 1449-1455, 2014.

[40] P. Sakdarat, J. Chongsuebsirikul, A. Phongphut et al., "Copper oxide nanorods pesticide sensor for methyl parathion detection," in The 19th International Conference on Nanotechnology (IEEE-NANO), pp. 113-116, Macao, China, 2019.

[41] C. V. Niveditha, M. J. J. Fatima, and S. Sindhu, "Comprehensive interfacial study of potentio-dynamically synthesized copper oxide thin films for photoelectrochemical applications," Journal of the Electrochemical Society, vol. 163, no. 6, pp. H426-H433, 2016.

[42] J. Chongsuebsirikul, P. Sakdarat, A. Phongphut et al., "Copper oxide nanorods electrodes for organophosphate pesticide sensor," in International Conference on Nano/Micro Engineered and Molecular Systems (IEEE-NEMS), pp. 520-523, Bangkok, Thailand, 2019.

[43] X. Wu, H. Bai, J. Zhang, F. E. Chen, and G. Shi, "Copper hydroxide nanoneedle and nanotube arrays fabricated by anodization of copper," The Journal of Physical Chemistry B, vol. 109, no. 48, pp. 22836-22842, 2005.

[44] D. J. Hamilton, Á. Ambrus, R. M. Dieterle et al., "Regulatory limits for pesticide residues in water (IUPAC Technical Report)," Pure and Applied Chemistry, vol. 75, no. 8, pp. 1123-1155, 2003. 